\title{
Evaluation of Bridge Abutment Capacity and Stiffness during Earthquakes
}

Rakesh K. Goel, M.EERI, and Anil K. Chopra, M.EERI

The "actual" capacity and stiffness values of the abutment-soil systems at the US 101/Painter Street Overpass, determined from its earthquake motions, are used to investigate how abutment stiffness varies during earthquakes and to evaluate current modeling procedures. It is found that the "actual" abutment stiffness may be significantly different during different phases of the shaking and decreases significantly as the abutment deformation increases. The CALTRANS modeling procedure leads to a good estimate of the transverse abutment stiffness and capacity. However, this procedure may overestimate the normal abutment stiffness and capacity by a factor of over two, indicating that the assumed value of $7.7 \mathrm{ksf}$ for the ultimate passive resistance of the soil, used in the CALTRANS procedure, may be too high. The AASHTO-83 and ATC-6 procedures lead to an initial estimate of the abutment stiffness that is too high in both directions.

\section{INTRODUCTION}

Most specifications and guidelines for earthquake design of highway bridges require that abutment-soil systems be included in the analytical model as discrete equivalent linear springs (CALTRANS, 1988 and 1989; ATC-6, 1981; AASHTO-83, 1988). In design applications, stiffness values of these springs are usually determined based either on simplified rules and an iterative process, or from abutment capacity and expected deformation during the earthquake. It is not entirely clear how well the stiffness value thus determined represents the complex behavior of the abutment-soil system, which is influenced by soil-structure interaction and nonlinear behavior of the soil. Therefore, it would be useful to compare the "design" values of abutment-soil stiffness with their "actual" values during earthquakes. A review of past studies on abutment stiffness indicates that this important goal is not always accomplished.

Wilson (1988), Levine and Scott (1989), and Wilson and Tan.(1990) proposed theoretical models for determining abutment stiffness based on the soil properties and abutment dimensions. However, these models do not include the significant effects of nonlinear soil

[RKG] Asst. Prof., Dept. of Civil \& Environmental Engineering, Syracuse University, Syracuse, NY 13244-1190. [AKC] Johnson Professor of Civil Engineering, University of California, Berkeley, CA 94720. 
behavior (Siddaharthan et al., 1995). Several researchers have attempted to determine the abutment stiffness and/or vibration properties from field vibration tests on highway bridges (Crouse et al., 1987; Gates and Smith, 1982; Douglas et al., 1990; Ventura et al., 1995). However, such small-amplitude tests lead to results that are nòt useful in design for intense earthquake motions, because the stiffness of the abutment depends on the level of shaking. Recognizing this limitation of small-amplitude tests, several investigations to estimate abutment stiffness from motions of bridges recorded during earthquakes have been reported (Romstad and Maroney, 1990; Maroney et al., 1990; McCallen and Romstad, 1994; Werner et al., 1994). The stiffness of the abutment is selected as the value that leads to a good match between the elastic earthquake response of a finite element model of the bridge and the motion recorded during the earthquake; the abutment-soil system is included as discrete linear elastic springs whose stiffness remains the same during the earthquake. While these studies led to improved understanding of the role of abutment-soil systems in earthquake response of bridges, the time-invariant linear elastic behavior of the abutment-soil systems assumed in these studies is not appropriate, because these systems may behave nonlinearly during intense ground shaking. Nonlinear analysis of abutment-soil systems may of course be accomplished by the finite element method (Sweet and Morill, 1993), but this approach is usually not suited to design applications.

In this investigation, the "actual" values of capacity and stiffness of the abutment-soil systems at the US 101/Painter Street Overpass are determined from the ground and structural motions recorded during earthquakes. These values are estimated from the force-deformation relations for the abutment-soil systems determined from the recorded motions using the dynamic equilibrium of the road deck. The abutment capacity and stiffness thus obtained include all effects, including those of soil-structure interaction and nonlinear behavior of the soil. These results are used to (1) investigate the effects of abutment deformation on the abutment stiffness and (2) evaluate the CALTRANS, AASHTO-83, and ATC- 6 procedures for estimating the abutment capacity and stiffness.

\section{STRUCTURE AND RECORDED MOTIONS}

The structure considered in this study is the US 101/Painter Street Overpass (Figure 1) located in Rio Dell, California. This 265-ft long bridge consists of a continuous reinforcedconcrete $(\mathrm{R} / \mathrm{C})$, multi-cell box-girder road deck supported on integral abutments at the two ends and on an R/C two-column bent. The bent divides the bridge into two unequal spans of $119 \mathrm{ft}$ and $146 \mathrm{ft}$. Both abutments and bent are skewed at an angle of $38.9^{\circ}$. The east abutment is monolithic with the superstructure and is supported by 14 driven 45 -ton concrete friction piles. The west abutment rests on a neoprene bearing strip that is part of a designed thermal expansion joint of the road deck. The foundation of this abutment consists of 16 driven 45-ton concrete friction piles. This bridge is typical of short bridges in California spanning two or four lanes separated highways.

The US 101/Painter Street Overpass was instrumented by the California Strong Motion Instrumentation Program (CSMIP) in 1977. Figure 1 also shows locations of the sensors and 
identifies the 20 data channels. Motions of this overpass have been recorded during nine earthquakes (Table 1), two of which have been selected here: the main shock of the April 25, 1992, Cape Mendocino/Petrolia earthquake and the second event of the November 21, 1986, Cape Mendocino earthquake. The first of these two earthquakes is an infrequent large event that may represent the design earthquake, and the latter is a frequent small event which may represent the service level earthquake. During the 1992 earthquake, the peak free-field accelerations were $0.38 \mathrm{~g}$ and $0.54 \mathrm{~g}$ in the longitudinal and transverse directions, respectively. These motions were amplified to $0.45 \mathrm{~g}$ in the longitudinal direction near the east end of the road deck and to $1.09 \mathrm{~g}$ in the transverse direction near the west end of the road deck. During the 1986 earthquake the much smaller free-field motions of $0.14 \mathrm{~g}$ and $0.12 \mathrm{~g}$ in the longitudinal and transverse directions were amplified to $0.18 \mathrm{~g}$ and $0.35 \mathrm{~g}$, respectively, at the road deck.

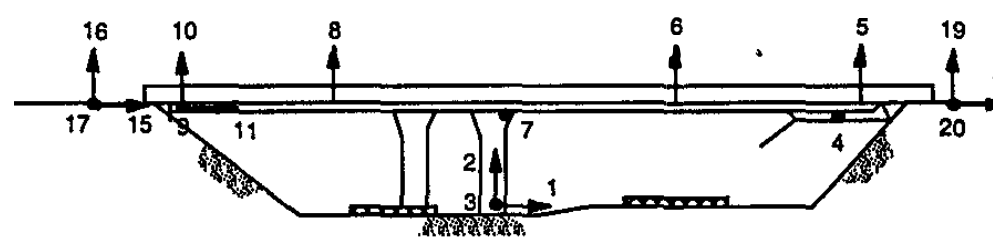

E-W Elevation
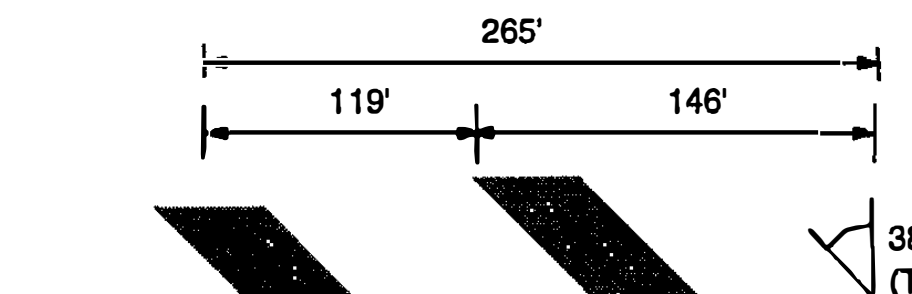

$38.9^{\circ}$ Skew (Typical)

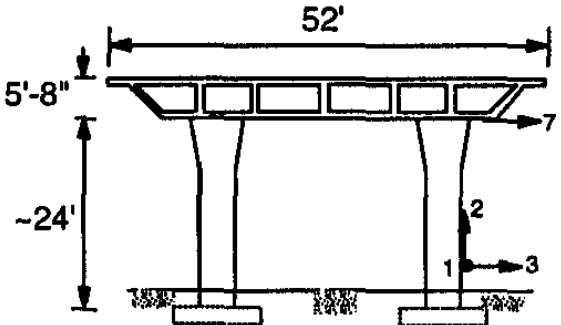

S-N Elevation
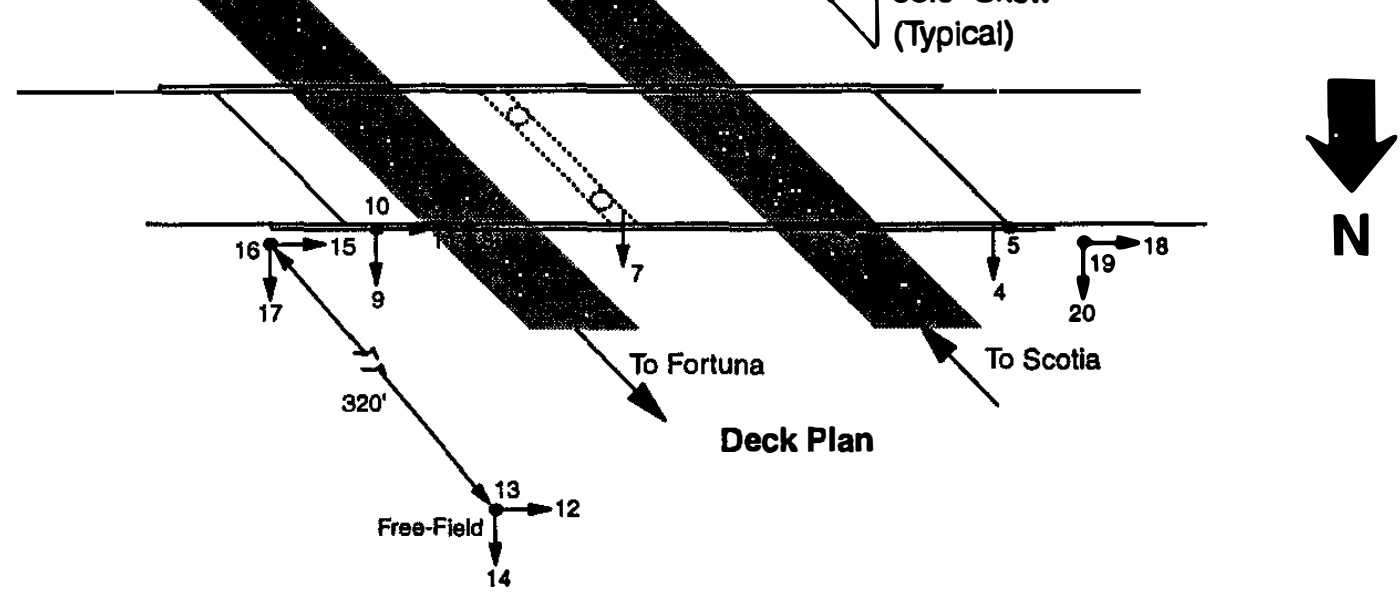

Figure 1. US 101/Painter Street Overpass: structural details and sensor locations.

\section{ANALYSIS PROCEDURE}

Presented in this section is the procedure to estimate abutment capacity and abutment stiffness from motions of highway bridges recorded during earthquakes. Described first is an approach for developing a structural idealization of the selected bridge. Next, the equations of dynamic equilibrium of the structural idealization are developed. Finally, methods to calculate abutment forces, deformations, capacity, and stiffness are described briefly; details are 
available elsewhere (Goel and Chopra, 1995). The simplifying assumptions introduced in this procedure are also identified.

Table 1. List of recorded motions at the US 101/Painter Street Overpass.

\begin{tabular}{||c|c|c|c|c|c|c||}
\hline No. & \multicolumn{1}{|c|}{ Earthquake } & $\begin{array}{c}\text { Depth } \\
(\mathrm{Km} .)\end{array}$ & $\begin{array}{c}\text { Mag. } \\
M_{L}\end{array}$ & $\begin{array}{c}\text { Dist. } \\
(\mathrm{Km} .)\end{array}$ & $\begin{array}{c}\text { Max. Hor. } \\
\text { FF Acc.(g) }\end{array}$ & $\begin{array}{c}\text { Max. Hor. } \\
\text { Str. Acc.(g) }\end{array}$ \\
\hline 1. & $\begin{array}{l}\text { Trinidad Offshore } \\
\text { 8 Nov, 1980 }\end{array}$ & 19 & 6.9 & 82 & 0.15 & 0.17 \\
\hline 2. & $\begin{array}{l}\text { Rio Dell } \\
\text { 16 Dec, 1982 }\end{array}$ & 5 & 4.4 & 15 & -- & 0.42 \\
\hline 3. & $\begin{array}{l}\text { Eureka } \\
\text { 24 Aug, 1983 }\end{array}$ & 30 & 5.5 & 61 & -- & 0.21 \\
\hline 4. & $\begin{array}{l}\text { Cape Mendocino } \\
\text { 21 Nov, 1986 (First Event) }\end{array}$ & 17 & 5.1 & 32 & 0.43 & 0.40 \\
\hline 5. & $\begin{array}{l}\text { Cape Mendocino } \\
\text { 21 Nov, 1986 (Second Event) }\end{array}$ & 18 & 5.1 & 26 & 0.14 & 0.35 \\
\hline 6. & $\begin{array}{l}\text { Cape Mendocino } \\
\text { 31 Jul, 1987 }\end{array}$ & 17 & 5.5 & 28 & 0.14 & 0.33 \\
\hline 7. & $\begin{array}{l}\text { Cape Mendocino/Petrolia } \\
\text { 25 Apr, 1992 }\end{array}$ & 18 & 6.2 & 42 & 0.52 & 0.76 \\
\hline 8. & $\begin{array}{l}\text { Cape Mendocino/Petrolia } \\
\text { 26 Apr, 1992 (AS \# 1) }\end{array}$ & 21 & 6.4 & 41 & 0.26 & 0.31 \\
\hline 9. & $\begin{array}{l}\text { Cape Mendocino/Petrolia } \\
\text { 26 Apr, 1992 (AS \# 2) }\end{array}$ & & & & 0.54 & 1.09 \\
\hline \hline
\end{tabular}

\section{STRUCTURAL IDEALIZATION}

Figure 2 shows the structural idealization of the US 101/Painter Street Overpass. The model consists of the road deck with three spring-damper systems, which represent the stiffness and damping properties of abutment-soil systems in the transverse direction at the east and west abutments and in the normal direction at the east abutment. The spring-damper system in the normal direction corresponds to the combined contribution of both abutments in this direction. The spring represents the stiffness property, and the damper accounts for material and radiation damping of the abutment-soil system. Each column in the central bent is represented by two linear elastic springs -- one normal to and the other along the bent. Each column in the bent is modeled explicitly to properly account for the contribution of the bent stiffness to the total torsional stiffness about the vertical axis of the overpass. Furthermore, the columns are assumed to be linearly elastic, because no cracking was observed in the columns even after the strongest shaking during the April 25, 1992, Cape Mendocino/Petrolia earthquake. 
The damper at the column location is excluded, because energy dissipation through material and radiation damping in the column foundation is expected to be much smaller compared to that at the abutments. This assumption is reasonable inspite of the suggestion in a recent study of the US 101/Painter Street Overpass that radiation damping through the bent foundation is important (Makris et al., 1994) because this conclusion was based on analyses assuming linearity of the entire system including the abutment-soil systems. However, abutment damage during the 1992 events and results presented later in this paper indicate that abutment-soil systems responded well into the inelastic range and dissipated significant energy through hysteretic action. Ignoring the hysteretic-energy dissipated by abutment-soil systems, as was the case in the study by Makris et al. (1994), is expected to overemphasize the importance of energy-dissipation requirement at the bent foundation.

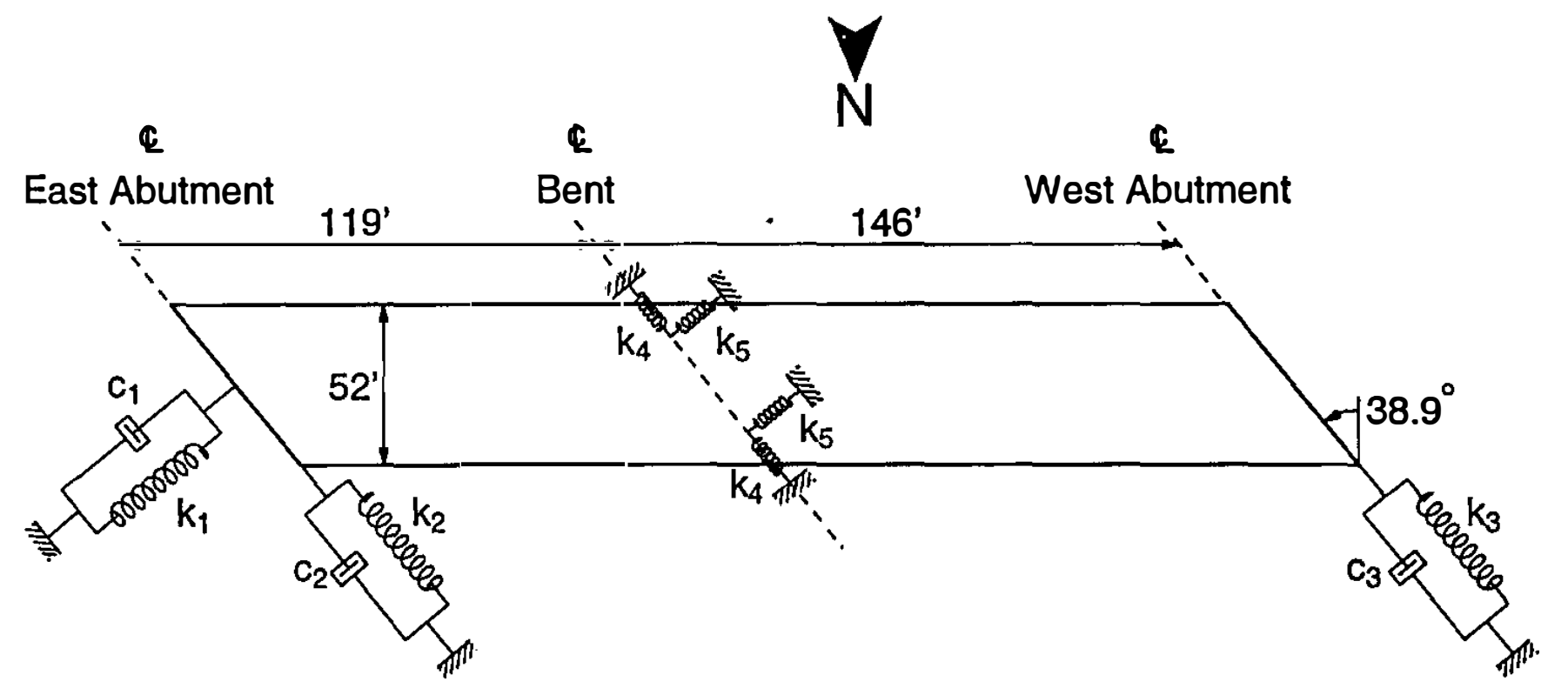

Figure 2. Idealized model of US 101/Painter Street Overpass.

\section{EQUATIONS OF DYNAMIC EQUILIBRIUM}

With reference to the free-body diagram of Figure 3, the three equations of dynamic equilibrium for this system in the $\mathrm{x}, \mathrm{y}$, and $\theta$ directions are:

$\mathrm{f}_{\mathrm{I}}+\mathrm{f}_{\mathrm{D}}+\mathrm{f}_{\mathrm{S}}=\mathbf{0}$

in which $\mathbf{f}^{T}=\left\langle f_{1 x}, f_{I y}, f_{I \theta}\right\rangle$ is the vector of inertia forces, $f_{D}$ is the vector of damping forces, and $\mathbf{f}_{S}$ is the vector of spring forces; $\mathbf{f}_{\mathrm{D}}$ and $\mathbf{f}_{\mathrm{S}}$ are formed by appropriately transforming forces at the abutments: $\left(f_{D 1}+f_{S 1}\right),\left(f_{D_{2}}+f_{S_{2}}\right)$, and $\left(f_{D_{3}}+f_{S 3}\right)$; and the forces at the columns: $\mathrm{f}_{\mathrm{S} 4}, \mathrm{f}_{\mathrm{S5}}, \mathrm{f}_{\mathrm{S} 6}$, and $\mathrm{f}_{\mathrm{S} 7}$ to the $\mathrm{x}, \mathrm{y}$, and $\theta$ coordinate system. 


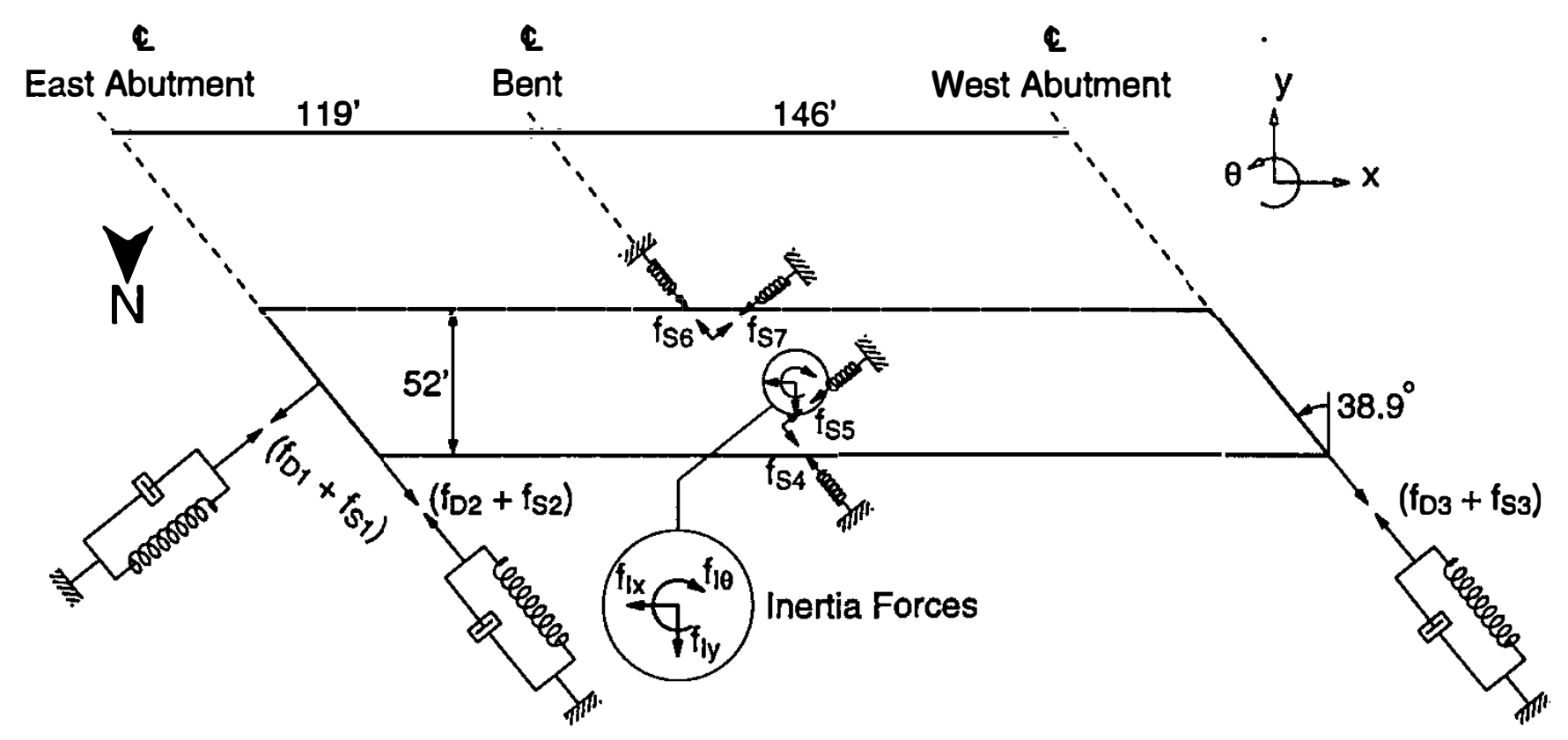

Figure 3. Free-body diagram for structural idealization of US 101/Painter Street Overpass.

\section{ABUTMENT FORCES AND DEFORMATIONS}

In the three equations represented by (1), all the forces except the resisting forces associated with the abutments are known. The inertia forces associated with the rigid-body motion of the road deck are computed from the mass properties of the deck and its recorded accelerations. The additional inertia forces due to the in-plane deformations of the road deck in the y-direction are included by assuming that the deformation over the length of the deck varies as a half-cycle of a sine function. Amplitude of the sine function is taken as in-plane deformation of the deck at its center of mass. The force in each column spring is calculated from its stiffness and deformation. The column stiffness in each of the two orthogonal directions is half of the bent stiffness along the respective direction. The stiffness along the bent is the lateral stiffness of a frame formed by the columns and the cap-beam. Similarly, stiffness normal to the bent is the lateral stiffness of a frame consisting of the columns and the road deck. In computing the frame stiffnesses the moment of inertia of the column is selected as its cracked value in the moment curvature relationship, and the moment of inertia values of the cap-beam and the box girder are obtained from their structural details. Additional details are available elsewhere (Appendices B to D of Goel and Chopra, 1995).

At each time-instant the deformation in an abutment spring-damper system or a column spring is obtained by subtracting the free-field displacement from the displacement at the top of the abutment or the column, respectively. The displacements are obtained by appropriately transforming displacements at the sensor positions to the desired locations. To calculate the column deformation, it would be more appropriate to subtract the motion at the column base, instead of the free-field motion, but the former is not available; note that sensors 1 and 3 (Figure 1) record motions at about one-quarter the column height, not at the base. 


\section{ABUTMENT CAPACITY AND STIFFNESS}

Solution of the three dynamic equilibrium equations, represented by (1), at each time instant leads to the abutment forces which can be plotted against the computed deformations to obtain the force-deformation hysteresis loops. Figure 4 shows such loops for the three abutment systems during the 1992 earthquake. The capacity of the abutment-soil system is the yield strength displayed by a flat-yield plateau in the hysteresis loops; further increase in the abutment force is due to strain hardening effects. The normal abutment capacity in the negative (east) direction can be estimated as about 1200 kips, the force at which the hysteresis loop exhibits a yield plateau in the left-lower quadrant (Figure 4a). The transverse capacities of the west abutment in both positive (south) and negative (north) directions are estimated to be about 1000 kips (Figure 4c). However, it is not possible to estimate the normal capacity in the positive (west) direction or the transverse capacity of the east abutment, because the abutment did not yield during the earthquake, as is evident by the lack of a yield plateau (Figures $4 \mathrm{a}$ and 4b).

The stiffness of the abutment-soil system is determined by isolating individual loops, such as the ones shown in Figure 5, from the force-deformation hysteresis loops of Figure 4. The first loop (Figure 5a) corresponds to that during a low-level of shaking, whereas the second (Figure 5b) represents that during the more intense shaking of the abutment-soil system. These hysteresis loops indicate that abutment-soil systems exhibit nearly viscoelastic behavior during low-level shaking evident from the nearly elliptical shape of the force-deformation relation of Figure 5a. During more intense ground shaking, however, these systems may respond nonlinearly, apparent from the elastic-plastic-strain-hardening characteristics of the forcedeformation relation in Figure 5b.

The stiffness of the abutment-soil system during low-level shaking may be estimated as a slope of the major axis of the elliptical loop. Two such values corresponding to an upper bound and a lower bound are shown in Figure 5a and indicate stiffness values of 13,115 and $11,000 \mathrm{kips} / \mathrm{ft}$. These values were obtained by visual inspection. The stiffness also could have been estimated from the expression for perfectly viscoelastic behavior: stiffness $=$ $\sqrt{\left(F_{o} \div \Delta_{o}\right)^{2}-\left(E_{D} \div \pi \Delta_{o}^{2}\right)^{2}}$, in which $F_{o}=\left|F_{\max }\right|+\left|F_{\text {min }}\right| / 2, \Delta_{o}=\left|\Delta_{\max }\right|+\left|\Delta_{\min }\right| / 2$, and $E_{D}$ is the area of the loop. However, this procedure was not used because it may not necessarily lead to a better estimate of the stiffness in light of some deviations of the recorded hysteresis loops from the idealized elliptical shape for perfectly viscoelastic behavior compared to the estimate by visual inspection. The stiffness of the abutment-soil system during the more intense shaking phase may be estimated as the secant slopes. Two such values, 7500 and $12000 \mathrm{kips} / \mathrm{ft}$ for the positive and negative deformations, respectively, are shown in Figure $5 \mathrm{~b}$.

\section{EFFECTS OF ABUTMENT DEFORMATION ON ABUTMENT STIFFNESS}

How the deformation of the abutment influences its stiffness is investigated next. The total deformation during a single hysteresis loop is defined as the sum of the deformation amplitudes in the positive and negative directions of the loop. Both stiffness and deformation 


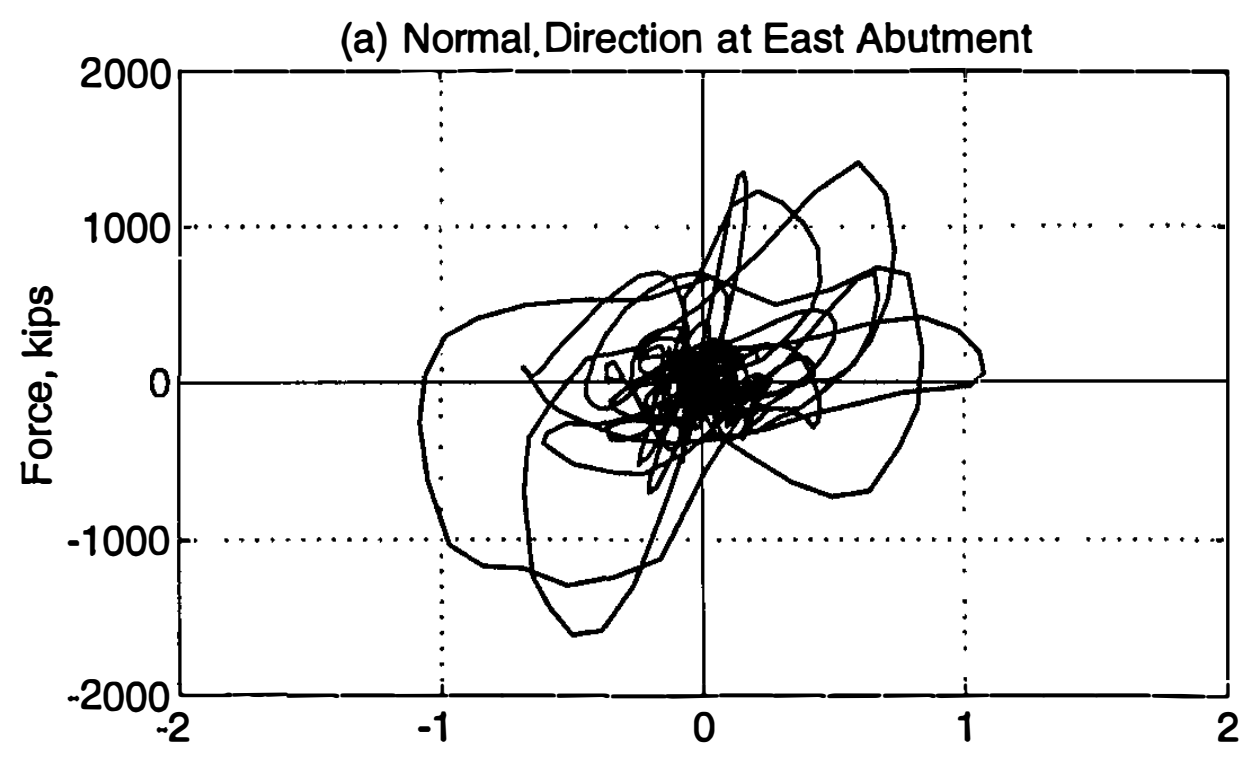

(b) Transverse Direction at East Abutment

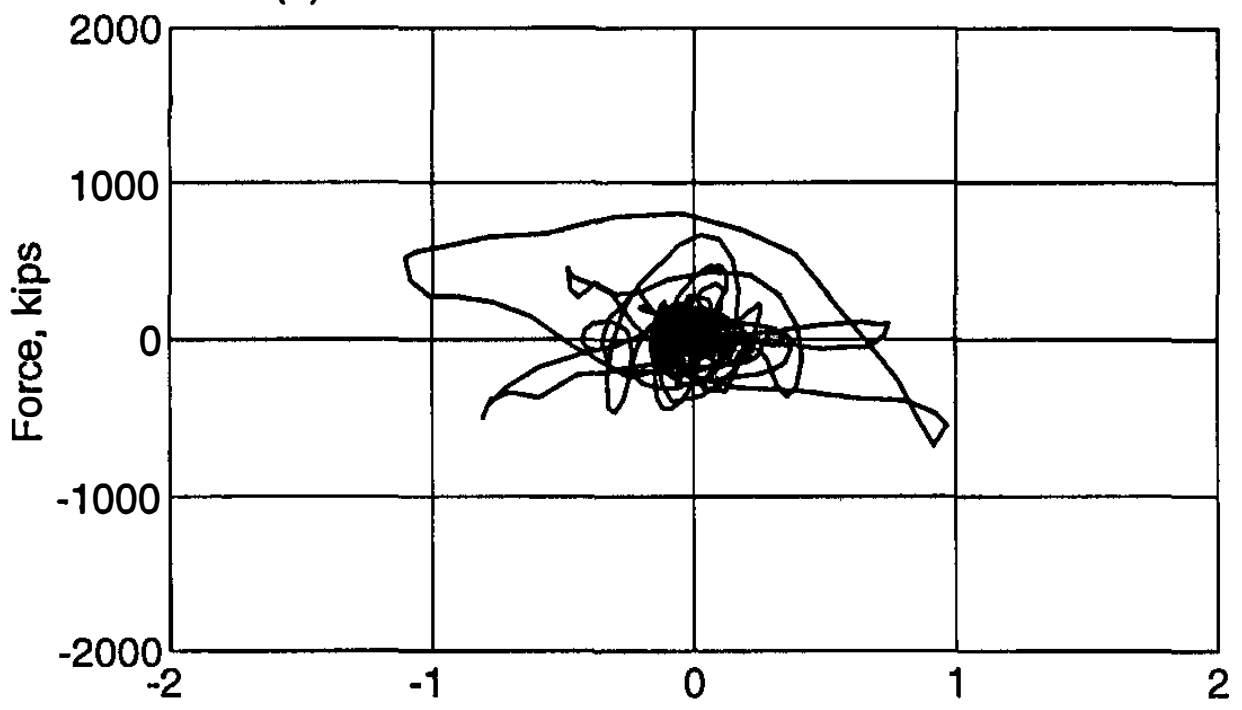

(c) Transverse Direction at West Abutment

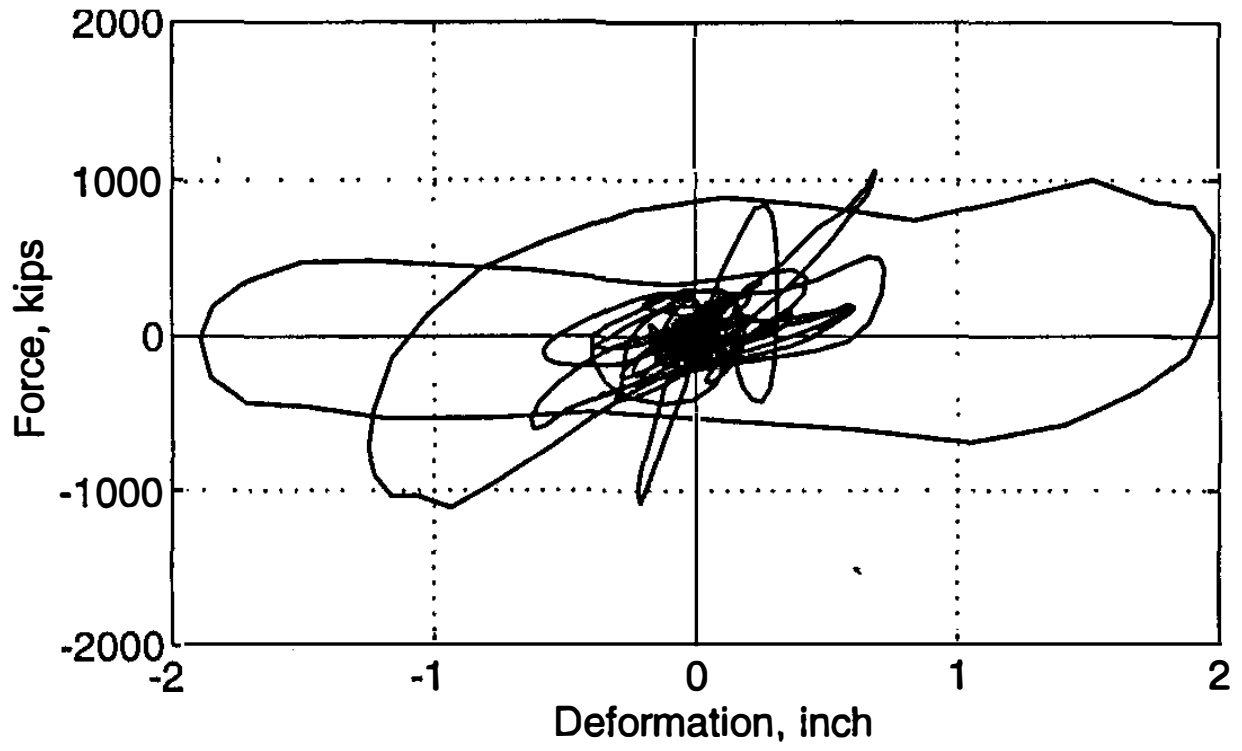

Figure 4. Abutment force-deformation relationships during the 1992 earthquake. 


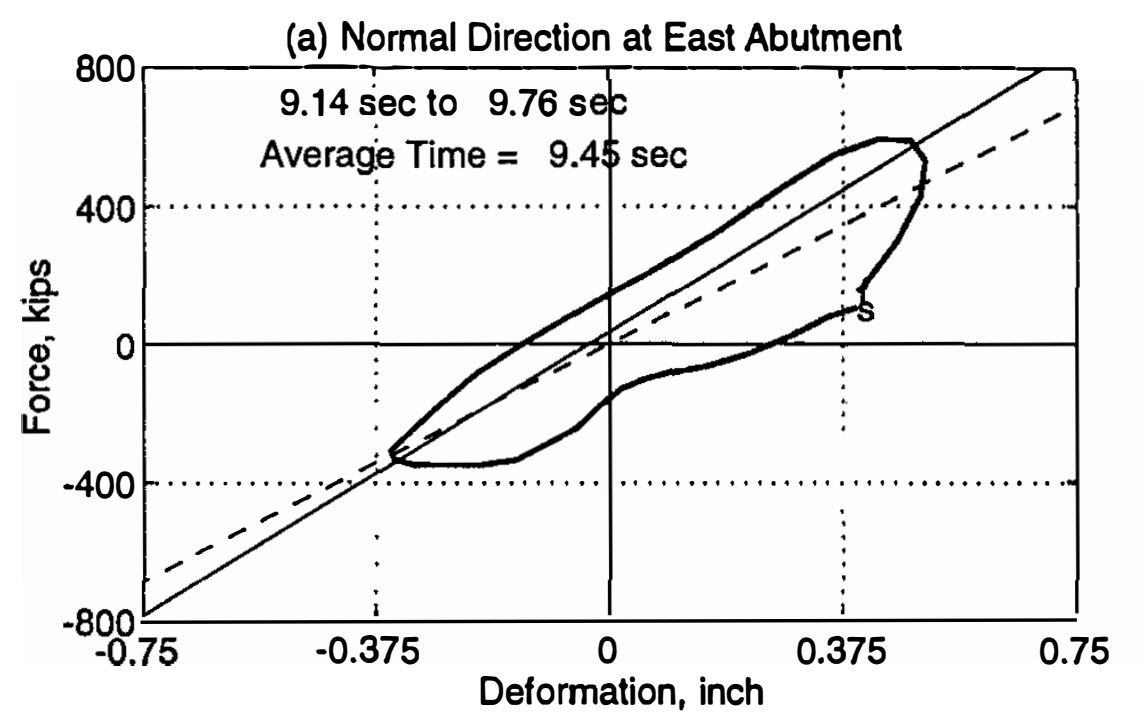

$$
\begin{gathered}
13115 \mathrm{kips} / \mathrm{ft} \\
-\ldots \ldots \ldots- \\
11000 \mathrm{kips} / \mathrm{ft}
\end{gathered}
$$

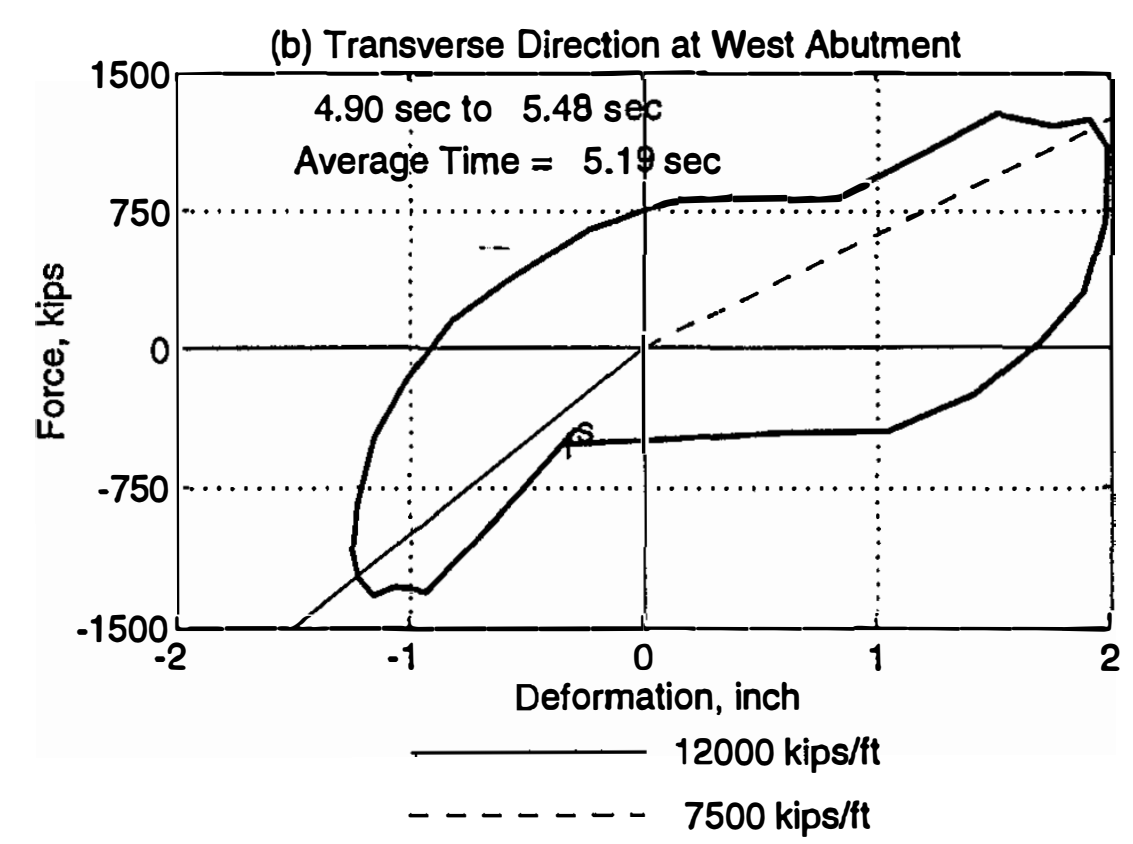

Figure 5. Estimation of abutment stiffness from the abutment force-deformation relationships.

of an abutment are determined from hysteresis loops at different time instants. Such properties during the intense shaking of the 1992 earthquake are presented and compared with those during the much smaller shaking of the 1986 earthquake.

It would also be useful to investigate frequency dependence of the abutment stiffness, particularly for low-level shaking for which the abutment-soil systems exhibit viscoelastic behavior (Figure 5a). However, this investigation was not possible, because a sufficient number of loops that are nearly elliptical (or exhibit very little nonlinearity) could not be isolated at different frequencies from the available data (Appendix E of Goel and Chopra, 1995). 


\section{TIME-VARIATION OF ABUTMENT DEFORMATION AND STIFFNESS}

Figure 6 shows the time-variation of the abutment stiffness (circles) with its scale on the left-hand side and of the total deformation (squares) with its scale on the right hand side; the upper and lower bound values of the stiffness are connected by a vertical line; the results presented are for the 1992 earthquake. These values, determined from a hysteresis loop as described in the preceding section, were plotted at the time instant when half of the loop had been completed. It is clear from these results that abutment stiffness, which depends on the deformation, varies significantly during the same earthquake. In particular, the results for normal stiffness at the east abutment (Figure 6a) show the following trends:

(1) The abutment tends to be stiff for the small deformations during the build-up phase of the shaking.

(2) Abutment stiffness decreases as its deformation increases during stronger shaking.

(3) The abutment recovers some of its stiffness with subsequent reduction in its deformation as the motion becomes less intense towards the latter part of the shaking.

(4) The stiffness recovery is only partial and gradual over time; the recovery is especially slow after repeated cycles of large deformation.

Some of these trends are present for the transverse stiffness at the east and the west abutments (Figure $6 \mathrm{~b}$ and $6 \mathrm{c}$ ). For example, results for transverse abutment stiffness at the west abutment exhibit trends (3) and (4) that are noted above. Other trends are expected to be the same. However, all these trends were not verified, because meaningful hysteresis loops could not be isolated for the latter two abutments and their stiffness values were not identified.

Some of the trends we observed are similar to the ones identified by Maroney et al. (1994) from experiments on half-scale abutments. They observed that the stiffness of the abutment decreases as its deformation increases. However, they could not identify the trends on the recovery of stiffness because the abutments were subjected to monotonically increasing deformation (or load) cycles.

The above-identified behavior of abutments during earthquakes indicates that the soil enclosed between the wingwalls provides significant resistance to the abutment motion for small deformation levels, but becomes less effective at larger deformations. Some of the reduction in stiffness at large deformations is due to the nonlinear behavior of the abutmentsoil system, apparent from the hysteresis loops of Figure 4.

\section{TIME-VARIATION OF ABUTMENT STIFFNESS DURING TWO EARTHQUAKES}

The abutment stiffness values during the intense shaking of the 1992 earthquake and the much smaller motions of the 1986 earthquake are compared in Figure 7. These results show that the abutment behavior is consistent with the trends identified in the previous section. The 
(a) Normal Direction at East Abutment 1992 Earthquake

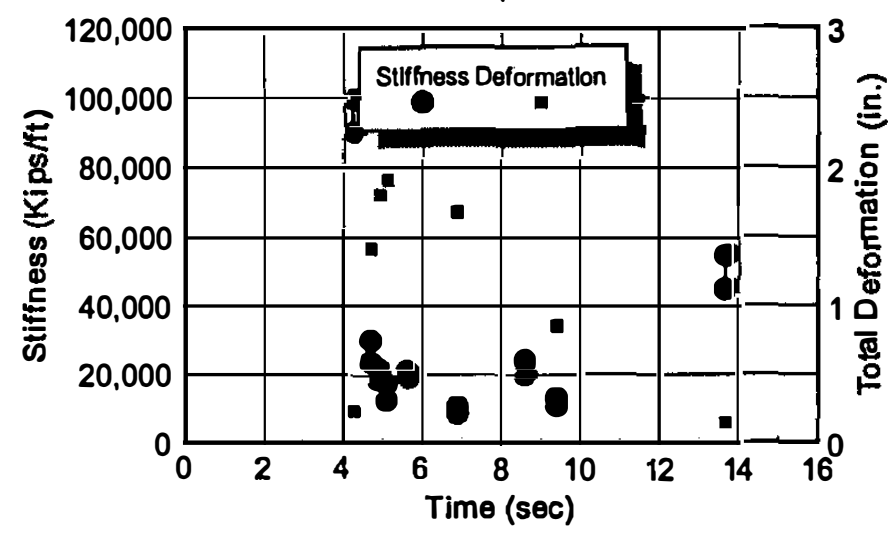

(b) Transverse Direction at East Abutment 1992 Earthquake

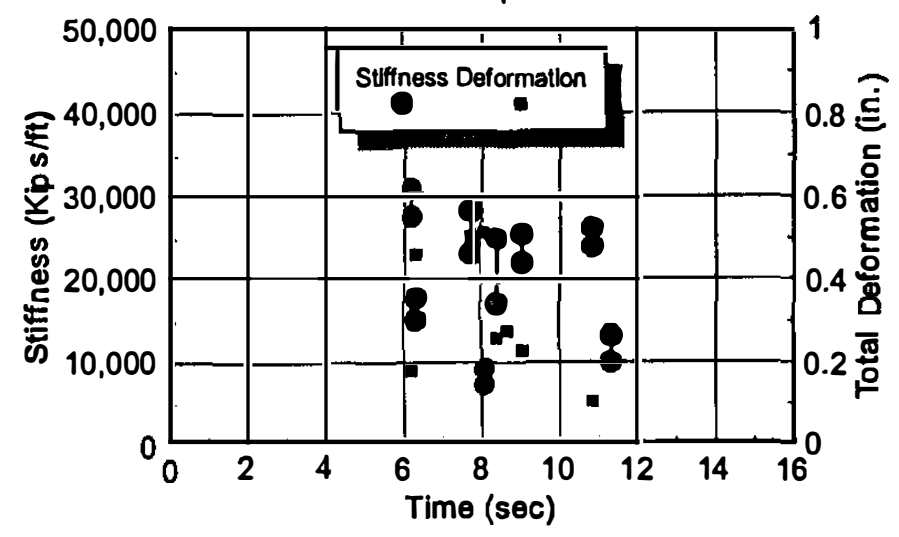

(c) Transverse Direction at West Abutment 1992 Earthquake

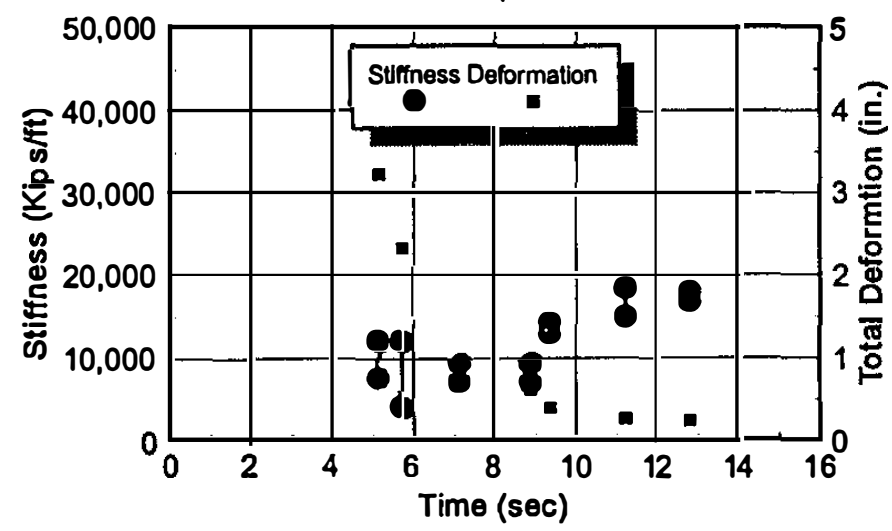

Figure 6. Time-variation of abutment stiffness and deformation during the 1992 earthquake.

abutment is generally less stiff during the 1992 earthquake (Figures 7a and 7c), because the abutment deformations are larger, compared to the 1986 earthquake; the peak abutment deformations during the former earthquake are almost ten times those during the latter earthquake (Goel and Chopra, 1995). This reduction in stiffness is more pronounced for the west abutment, because its deformations are larger due to torsional motions of the road deck during the 1992 earthquake. If the deformations during the two earthquakes are similar, as in 
the transverse direction at the east abutment, the abutment stiffnesses are also similar (Figure 7b).

(a) Normal Direction at East Abutment

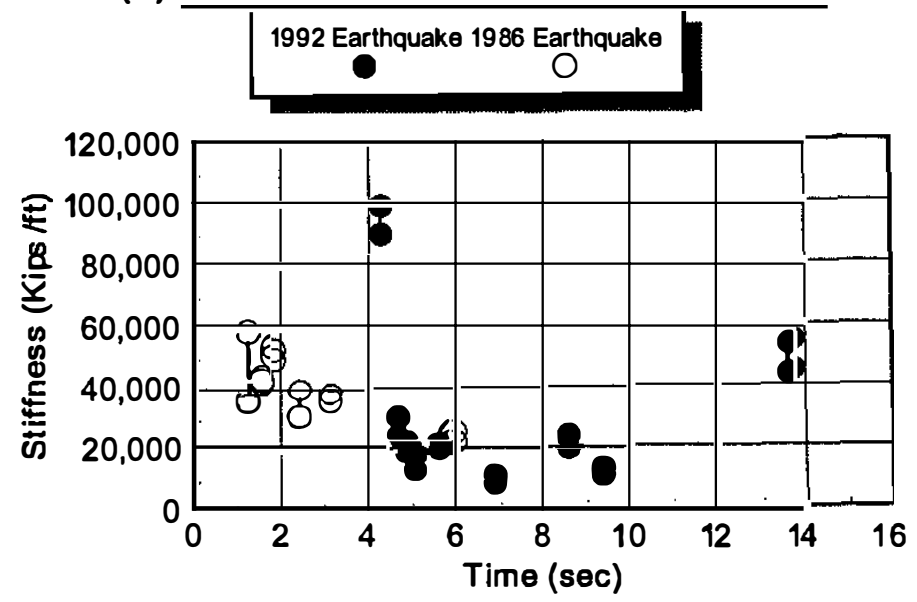

(b) Transverse Direction at East Abutment

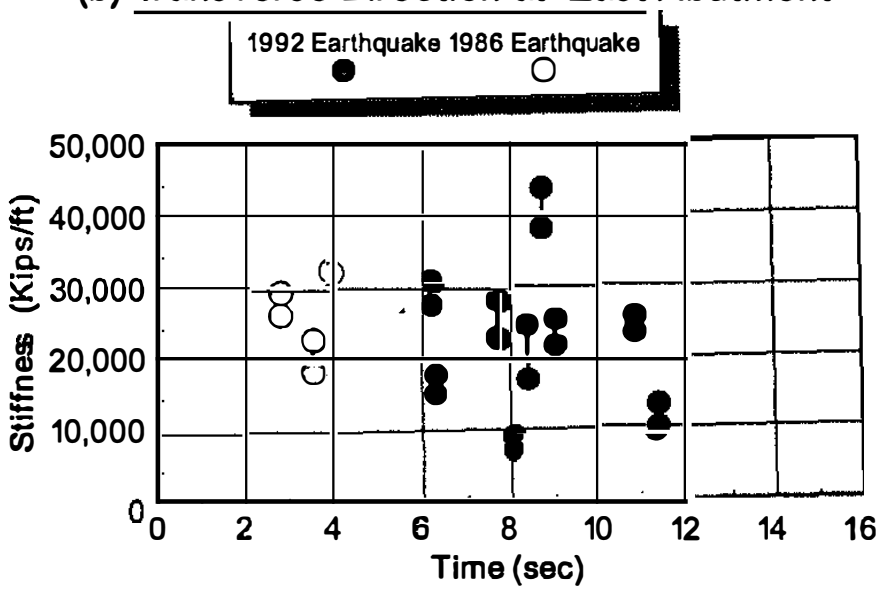

(c) Transverse Direction at West Abutment

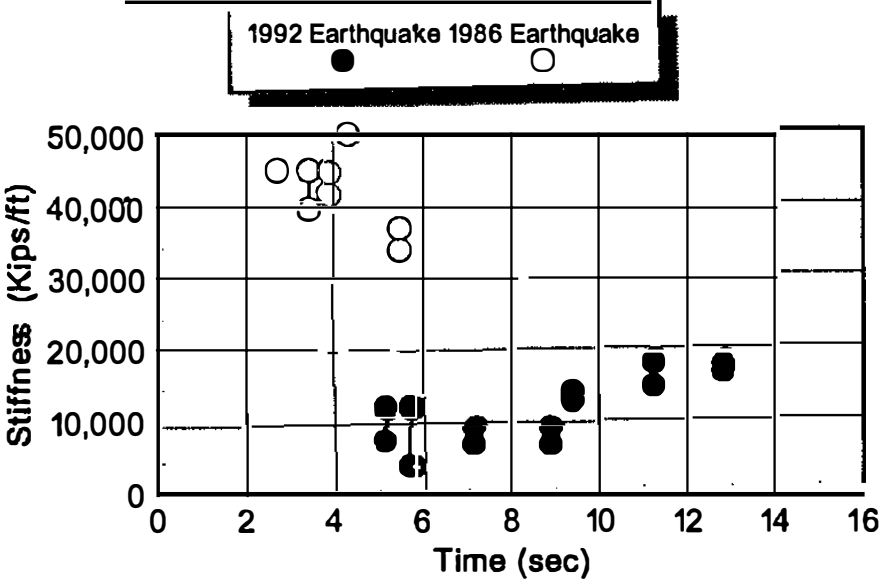

Figure 7. Time-variation of abutment stiffness during the 1992 and 1986 earthquakes. 


\section{TORSIONAL MOTIONS OF THE ROAD DECK}

The road deck of the US 101/Painter Street Overpass experienced significant torsional motions (or rotation) about its vertical axis during the main shock of the 1992 Cape Mendocino/Petrolia earthquake; the peak acceleration at the west end of the road deck was more than 1.5 times that at the east end during this earthquake (Shakal et al., 1992). In order to investigate the cause of this behavior of the road deck, the transverse stiffnesses of the east and the west abutments are compared in Figure 8. The transverse stiffness of the west abutment is significantly smaller compared to the east abutment for two reasons. First, the two abutments have the same plan dimensions, but the west abutment is taller. Second, the east abutment is constructed monolithically with the footing, while the west abutment is seated on a neoprene bearing to permit thermal movement that introduces additional flexibility at the west abutment. Because of the difference in the two abutment stiffnesses, the center of rigidity of the deck is closer to the east abutment; however, the center of mass is located close to midway between the two abutments. The resulting eccentricity between the centers of mass and rigidity contributed to the torsional motion of the deck. As shown earlier (Goel and Chopra, 1990), the motion should be larger on the flexible side, the west abutment, and this is consistent with the recorded motions. Eccentricity in the overall stiffness of the bridge system due to eccentric location of the bent and the normal abutment stiffness also contributed to the torsional motions of the road deck.

Comparison of Transverse Stiffnesses 1992 Earthquake

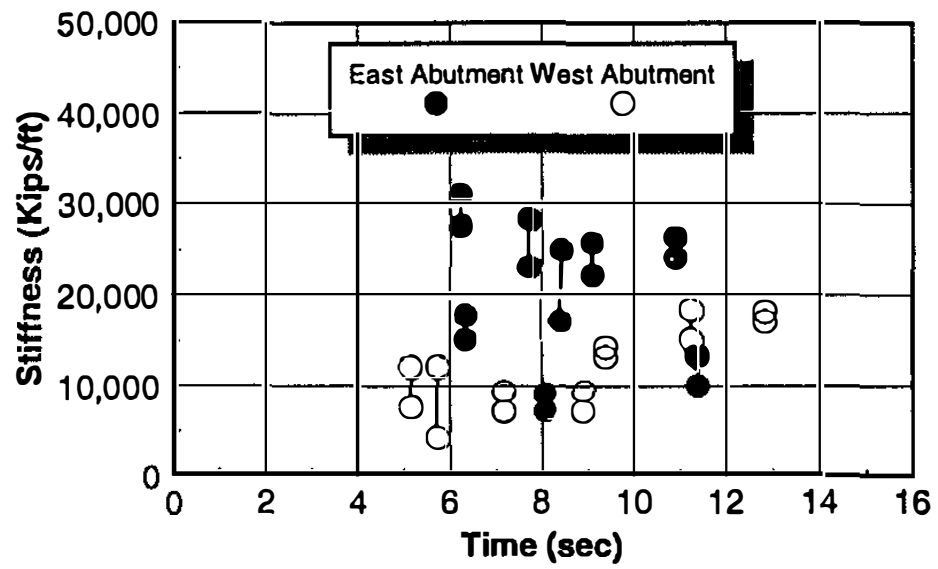

Figure 8. Transverse stiffness of the east and the west abutment during the 1992 earthquake.

\section{EVALUATION OF CURRENT PROCEDURES}

The "design" values of the abutment capacity and abutment stiffness, computed by the CALTRANS, AASHTO-83, and ATC-6 procedures, are compared in this section with their "actual" values, obtained by the aforementioned procedure applied to the 1992 earthquake records. Described first are the current procedures to calculate the "design" values, followed by a comparison of the "design" and "actual" values of the abutment capacity and abutment stiffness. 


\section{CURRENT PROCEDURES}

In the CALTRANS procedure, the "design" value of the abutment capacity in the longitudinal direction is computed as the sum of the resistance values provided by the foundation and the soil behind the backwall. It is assumed that the backfill is mobilized to a depth equal to the depth of the superstructure and that the ultimate passive resistance of the backfill is equal to $7.7 \mathrm{ksf}$ (CALTRANS, 1989). Since the foundation capacity depends on which of its components fails first, its value is calculated for the following four cases:

(1) Diaphragm at the monolithic east abutment reaches its shear capacity.

(2) Piles at the east abutment reach their peak lateral resistance values.

(3) Diaphragm at the east abutment reaches its shear capacity and the piles at the west abutment reach their peak lateral resistance values.

(4) Piles at the east and west abutments reach their peak resistance values.

The first two cases correspond to resistance provided only by the foundation at one abutment before the expansion joint gap closes or after the longitudinal shear key at the west abutment fails, whereas the other two cases correspond to resistance provided by both the abutments when the shear key is engaged at the west abutment. The first and third cases assume shear failure in the backwall just below the road deck sof fit before the piles fail, whereas the second and the fourth cases assume failure of piles before the backwall fails. The "design" value of the abutment capacity in the transverse direction is computed as the sum of the shear capacity of one wingwall and the foundation capacity. The foundation capacity for the monolithic east abutment is assumed to be equal to the peak resistance offered by the piles, whereas that for the west abutment it is taken to be equal to the capacity of the transverse shear key. As specified in the CALTRANS Bridge Design Aids, the capacity of the shear key is computed as 0.75 times the peak resistance offered by the piles. The resulting "design" values of the abutment capacity are presented in Table 2.

In the CALTRANS procedure, the "design" value of the abutment stiffness is computed as the ratio of its "design" capacity and the acceptable deformation. Two values of the acceptable abutment deformations are considered: 1 inch and 2.4 inch. The first represents the deformation at which the soil pressure reaches its peak value of $7.7 \mathrm{ksf}$, and the latter represents the limiting value corresponding to incipient damage to the abutment (CALTRANS, 1988 and 1989). The "design" values of the abutment stiffness are also summarized in Table 2. We have not included the iterative procedure in which the initial stiffness is computed by assuming the soil stiffness of $200 \mathrm{kips} / \mathrm{in}$ per linear foot of the abutment backwall or wingwall (Tsai et al., 1993; CALTRANS, 1988), because CALTRANS engineers no longer use this procedure.

In the AASHTO-83 and ATC- 6 procedures, which are identical, two estimates - initial and final -- for the "design" value of the abutment stiffness are calculated. The initial estimate of the abutment is obtained by adding the contributions of the backfill and of the piles (Lam 
and Martin, 1986). The stiffness due to the backfill is $0.425 \times E_{s} \times B$, in which $E_{s}=1440 \mathrm{ksf}$ is the elastic modulus of the soil and $B$ is the width of the backwall or effective length of the backwall or the wingwall. The stiffness of each pile is assumed to be equal to $40 \mathrm{kips} / \mathrm{inch}$. The resulting initial estimates of the abutment stiffness in the longitudinal and the transverse direction are $48592 \mathrm{kips} / \mathrm{ft}$ and $15758 \mathrm{kips} / \mathrm{ft}$, respectively. The final stiffness value is obtained by an iterative procedure in which the abutment stiffness is successively reduced until the computed abutment force does not exceed the abutment capacity. Although AASHTO83/ATC-6 specifications mention that the abutment capacity may be computed from ultimate resistance values of the soil and the piles, guidelines for these computations are lacking. If the abutment capacity is assumed equal to the "design" capacity that is computed by the CALTRANS procedure, the final value of the "design" stiffness by the AASHTO-83/ATC-6 procedure also would be the same as in Table 2. Detailed calculations for the CALTRANS and AASHTO-83/ATC-6 procedures are presented in Appendix A.

It is useful to note that the above described procedures are subject to interpretation by design engineers and they may use alternate values of above mentioned parameters or slightly modified procedures based on judgment for this purpose.

Table 2. Abutment capacity and stiffness from CALTRANS procedure.

\begin{tabular}{|c|c|c|c|c|}
\hline Direction & $\begin{array}{c}\text { Acceptable } \\
\text { Deformation } \\
\text { (inch) }\end{array}$ & Case & $\begin{array}{l}\text { Abutment } \\
\text { Capacity } \\
\text { (Kips) }\end{array}$ & $\begin{array}{l}\text { Stiffness } \\
\text { (Kips/ft) }\end{array}$ \\
\hline \multirow[t]{8}{*}{ Normal } & \multirow[t]{4}{*}{1.0} & 1 & 3,663 & 43,960 \\
\hline & & 2 & 3,016 & 36,188 \\
\hline & & 3 & 4,383 & 52,600 \\
\hline & & 4 & 3,655 & 43,868 \\
\hline & \multirow[t]{4}{*}{2.4} & 1 & 3,663 & 18,317 \\
\hline & & 2 & 3,016 & 15,078 \\
\hline & & 3 & 4,383 & 21,917 \\
\hline & & 4 & 3,655 & 18,278 \\
\hline \multirow{2}{*}{$\begin{array}{c}\text { Transverse } \\
\text { East }\end{array}$} & 1.0 & \multirow{2}{*}{\multicolumn{2}{|c|}{932}} & 11,187 \\
\hline & 2.4 & & & 4,661 \\
\hline \multirow{2}{*}{$\begin{array}{c}\text { Transverse } \\
\text { West }\end{array}$} & 1.0 & \multirow{2}{*}{\multicolumn{2}{|c|}{879}} & 10,553 \\
\hline & 2.4 & & & 4,397 \\
\hline
\end{tabular}

\section{ABUTMENT CAPACITY}

The lower and upper bound values of the "design" abutment capacity in the normal direction, obtained by the CALTRANS procedure, are 3016 and 4383 kips, respectively (Table 2). As mentioned previously, the "actual" value estimated from the force-deformation 
relationship is only about 1200 kips. Clearly, the "design" value of the abutment capacity in the normal direction is over twice the estimate for the "actual" value during the earthquake. The calculations presented in Appendix A indicate that a major portion of the abutment capacity in this direction is provided by the passive soil resistance: for case 2 the passive soil resistance contributes 2456 kips, which is about $81 \%$ of the total abutment capacity of 3016 kips. Therefore, it seems that the abutment capacity is overestimated in the CALTRANS procedure primarily due to overestimation of the passive soil resistance, implying that the assumed value of $7.7 \mathrm{ksf}$ for the ultimate passive resistance of the soil may be too high.

The "design" capacity of the west abutment in the transverse direction of 879 kips (Table 2) compares well with the previously identified value of about 1000 kips during the earthquake. Thus the CALTRANS procedure leads to a reasonable estimate of the transverse abutment capacity. During the earthquake the east abutment did not yield in the transverse direction. Therefore, its "actual" capacity could not be identified and is not compared with the "design" capacity.

Since the "design" values from the AASHTO-83/ATC-6 and the CALTRANS procedure are identical, the above-noted conclusions regarding the CALTRANS procedure also apply to the AASHTO-83/ATC-6 procedure.

\section{ABUTMENT STIFFNESS}

Compared in Figure 9a are the "design" values of the normal abutment stiffness normal at the east abutment obtained by the CALTRANS procedure and the "actual" values estimated from the recorded motions. For each deformation level, the "design" values are shown for the four possible failure modes of the abutments mentioned earlier; note that the figure shows only three lines, because the stiffnesses for two of the four failure modes are almost identical (Table 2).

These results show that during the strong shaking phase, the "design" values obtained by the CALTRANS procedure using 1-inch deformation are much larger than the "actual" values estimated from the recorded motions. However, the "design" values based on 2.4-inch deformation tend to be close to the "actual" values. The peak deformation normal to the east abutment during the 1992 earthquake was about 1 inch in both positive and negative directions (Figure 4a). Thus comparison of the "design" value calculated for the actual earthquake induced deformation of 1-inch shows that the CALTRANS overestimates normal stiffness by a factor of over two. This is consistent with the previous observation that the CALTRANS procedure overestimates the abutment capacity by a factor of over two. During beginning and ending phases of the earthquake, when ground shaking is less intense, the actual deformation of the abutment is small and the CALTRANS procedure using either deformation level underestimates the stiffness.

Results for the transverse stiffness of the east abutment show that the "design" value of the stiff ness from the CALTRANS procedure for either deformation level may be significantly smaller than the "actual" values during the earthquake (Figure 9b). This difference can be 
explained by noting that the earthquake-induced deformations were significantly smaller along the east abutment (Figure 4b), compared to those assumed by the CALTRANS procedure.

(a) Normal Direction at East Abutment 1992 Earthquake

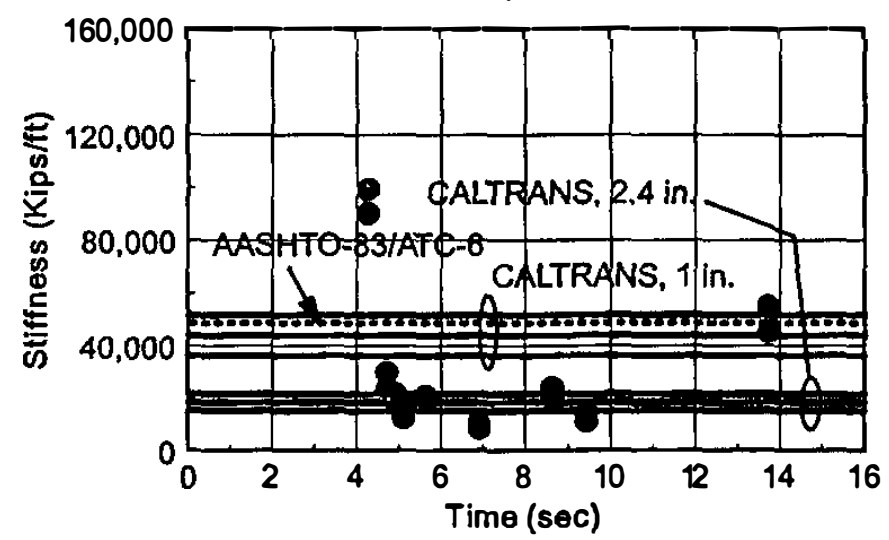

(b) Transverse Direction at East Abutment 1992 Earthquake

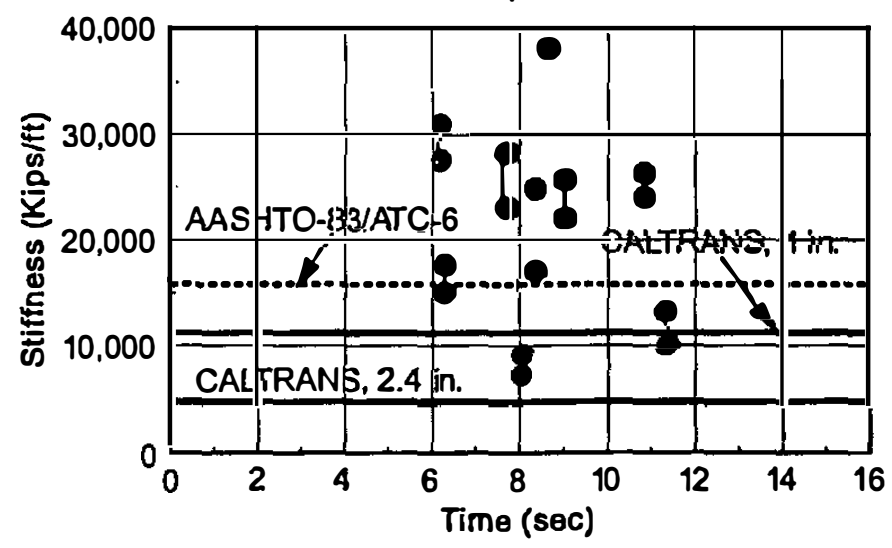

(c) Transverse Direction at West Abutment 1992 Earthquake

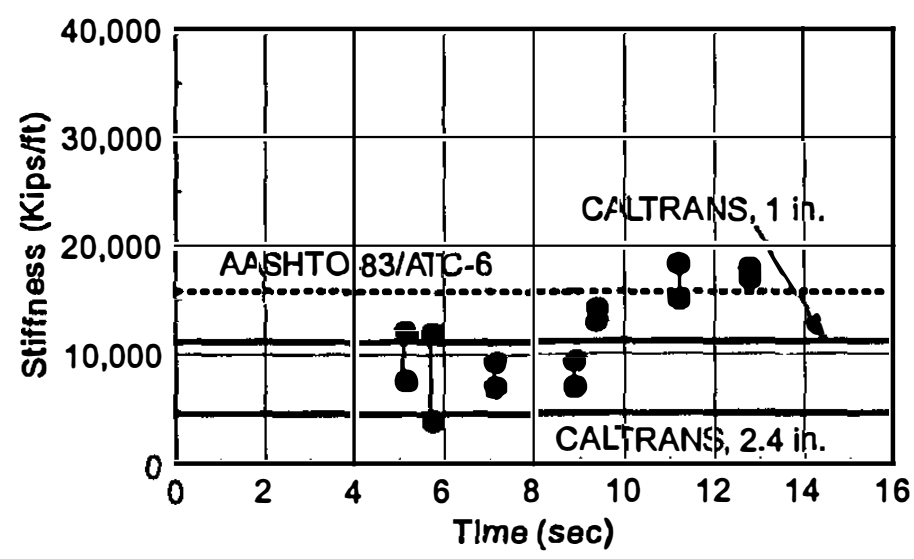

Figure 9. Comparison of "design" and "actual" values of abutment stiffness.

For the west abutment, the "design" values by the CALTRANS procedure for the two deformation levels form the upper and lower bounds of the "actual" stiffness values during the strong shaking phase (Figure 9c). Since the deformation of this abutment during the earthquake 
ranged between 1 inch and 2.4 inch (Figure 4c), the CALTRANS procedure leads to a good estimate of abutment stiffness in the transverse direction. The CALTRANS procedure using either deformation level may underestimate stiffness during the less intense motions near the end of the shaking, because the deformation of the abutment is small.

The above observations regarding the CALTRANS design value of abutment stiffness also apply to the final value of stiffness from the AASHTO-83/ATC-6 procedure. However, the AASHTO-83/ATC-6 procedure gives initial estimates of the stiffness normal to the east abutment and stiffness along the west abutment that are larger than the "actual" stiffness during the strong shaking phase of the earthquake (Figure 9). During the build-up phase and towards the end of the earthquake, however, the initial estimate may be reasonable. The initial estimate of the stiffness along the east abutment is larger than the "actual" value, because the deformations of this abutment are small during the earthquake.

\section{CONCLUSIONS}

In this investigation the capacity and stiffness values of the abutment-soil systems at the US 101/Painter Street Overpass are determined from the ground and structural motions recorded during earthquakes, using a simple equilibrium-based approach without finite-element modeling of the structure or of the abutment-soil systems. The values determined in this manner, which include the effects of soil-structure interaction and of nonlinear behavior of the soil, indicate that the abutment stiffness varies with time, decreasing significantly as the abutment deformation increases. The road deck of this structure experienced significant torsional motions, in part because of the differences in transverse stiffnesses of the two abutments.

Evaluation of the current design procedures indicates that the CALTRANS procedure leads to a good estimate of the transverse abutment stiffness, provided the deformation assumed in computing the stiffness is close to the actual deformation during the earthquake. The CALTRANS procedure also leads to good estimate of the abutment capacity in this direction. However, this procedure may overestimate the normal abutment capacity and stiffness by a factor of over two, indicating that the assumed value of $7.7 \mathrm{ksf}$ for the ultimate passive resistance of the soil used in the CALTRANS procedure may be too high. The AASHTO-83/ATC- 6 procedure gives an initial estimate of abutment stiffness that is too large in both directions. Since the abutment capacities by the AASHTO-83/ATC-6 procedure are identical to those by the CALTRANS procedure, both procedures give identical values for the final stiffness.

These conclusions are based on results from recorded motions of one freeway overpass during two earthquakes. Similar analyses of recorded motions of other similar structures should be useful in verifying these conclusions and improving current design procedures. 


\section{ACKNOWLEDGMENTS}

This investigation was funded jointly by the Strong Motion Instrumentation Program, California Division of Mines and Geology and the California Department of Transportation. This support is gratefully acknowledged. Also acknowledged is the assistance provided by Bob Darragh, Moh-Jiann Huang, Praveen Malhotra, and Anthony Shakal in obtaining structural plans and earthquake records, and by Pat Hipley in implementing the CALTRANS procedure to calculate abutment stiffnesses. The valuable comments of the anonymous reviewers of the paper are also acknowledged.

\section{APPENDIX A: "DESIGN" CAPACITY AND STIFFNESS OF ABUTMENT}

Presented in this appendix are the calculations for abutment capacity and stiffness using the CALTRANS, AASHTO-83 and ATC-6 procedures. The results are presented first for the CALTRANS procedure, followed by the AASHTO-83/ATC- 6 procedure.

\section{CALTRANS PROCEDURE}

The "design" values of the abutment capacity and stiffness are determined by the procedure presented in Memo 5-1 of CALTRANS (1988). Since it is usually impractical to structurally size the abutment backwall below the soffit of the superstructure in order to totally mobilize the backfill, the CALTRANS procedure suggests calculating the abutment capacity based on mobilizing the backfill equal to the depth of the superstructure. The ultimate passive resistance of $7.7 \mathrm{ksf}$ is recommended for the backfill; for backfill depth smaller than 8 feet, the resistance may be reduced by a factor of $\sqrt{h / 8}$, in which $h$ is the actual depth of the backfill. The ultimate capacity of the Class 45 piles used in the abutment foundation of the US 101/Painter Street Overpass is assumed to be 40 kips. Both the backfill and the pile are assumed to reach their ultimate capacity at a deformation of one inch. As noted on the as-built plans, the compressive strength of the concrete is taken as 3500 psi. The "design" abutment stiffness is computed as a ratio of the "design" capacity and the acceptable deformation in the abutment.

\section{Normal Direction at East Abutment}

Required in computing the "design" capacity normal to the east abutment for four previously described cases are (a) the ultimate resistance of the soil, Rsorl, (b) shear capacity of the diaphragm, VDIA, (c) resistance of the piles at the east abutment, RPILES,E, and (d) resistance of the piles at the west abutment, RPILES,w. These capacities are:

$$
\begin{aligned}
\text { RsolL } & =(\sqrt{\mathrm{h} / 8}) \times 7.7 \mathrm{ksf} \times \text { Area }=(\sqrt{5.667 / 8}) \times 7.7 \mathrm{ksf} \times(5.667 \times 66.875) \\
& =2455.66 \mathrm{kips}
\end{aligned}
$$




$$
\begin{aligned}
\mathrm{V}_{\text {DIA }} & =\Phi_{n}\left(0.95 \sqrt{f_{c}^{\prime}}\right) \times \text { Area }=0.85 \times(0.95 \sqrt{3500}) \times(2.625 \times 66.875) \times 144 / 1000 \\
& =1207.65 \mathrm{kips}
\end{aligned}
$$

RPILES, $\mathrm{E}=$ No. of Piles $\times 40$ kips $=14 \times 40$

$$
=560 \mathrm{kips}
$$

RILES, $\mathrm{w}=$ No. of Piles $\times 40 \mathrm{kips}=16 \times 40$

$$
=640 \mathrm{kips}
$$

The values of "design" capacity normal to the east abutment for the four cases are:

Case 1: $\mathrm{EQ}_{\mathrm{L}}=\mathrm{R}_{\text {SOIL }}+\mathrm{V}_{\mathrm{DIA}}=2455.66+1207.65=3663.31 \mathrm{kips}$

Case 2: $\mathrm{EQ}_{\mathrm{L}}=\mathrm{RsOIL}+\mathrm{R}_{\mathrm{PILES}, \mathrm{E}}=2455.66+560=3015.66 \mathrm{kips}$

Case 3: $\mathrm{EQ}_{\mathrm{L}}=\mathrm{R}_{\text {soIL }}+\mathrm{V}_{\mathrm{DIA}}+\mathrm{R}_{\mathrm{PILES}, \mathrm{E}}=2455.66+1207.65+640=4383.31$ kips

Case 4: $\mathrm{EQ}_{\mathrm{L}}=\mathrm{R}_{\text {SOIL }}+\mathrm{R}_{\mathrm{PILES}, \mathrm{E}}+\mathrm{R}_{\mathrm{PILES}, \mathrm{w}}=2455.66+560+640=3655.66 \mathrm{kips}$

Dividing these capacities by the acceptable deformation of $0.2 \mathrm{ft}$ ( 2.4 inch) leads to "design" stiffness values of $18317,15078,21917$, and $18278 \mathrm{kips} / \mathrm{ft}$. Similarly, the "design" values of stiffness for the $1 / 12 \mathrm{ft}$ ( 1 inch) deformation are 43960, 36188, 52600, and $43868 \mathrm{kips} / \mathrm{ft}$.

\section{Transverse Direction at East Abutment}

The "design" capacity of the integral east abutment is calculated based on the shear capacity of one wingwall, $V_{W W}$, and resistance of piles, $R_{P I L E S, E}$. The shear capacity of one wingwall is:

$$
\begin{aligned}
\mathrm{V}_{\mathrm{wW}} & =0.85 \times\left(V_{c}+V_{s}\right)=0.85 \times\left(0.95 \sqrt{f_{c}^{\prime}}\right) \times \text { Area }+0.85 \times \frac{A_{v} f_{y} d}{S} \\
& =0.85 \times 56.28 \times(0.75 \times 11.5 \times 144) / 1000+0.85 \times(2 \times 0.2) \times 60 \times 11.5 / 0.7 \\
& =372.21 \mathrm{kips} \\
\mathrm{EQ}_{\mathrm{T}} & =\mathrm{V}_{\mathrm{wW}}+\mathrm{R}_{\mathrm{PILES} . \mathrm{E}}=372.21+560 \\
& =932.21 \mathrm{kips}
\end{aligned}
$$

Dividing this capacity by $0.2 \mathrm{ft}$ ( $2.4 \mathrm{inch}$ ) leads to "design" stiffness of $4661 \mathrm{kips} / \mathrm{ft}$. Similarly, the stiff ness corresponding to $1 / 12 \mathrm{ft}$ ( 1 inch) deformation is $11187 \mathrm{kips} / \mathrm{ft}$.

\section{Transverse Direction at West Abutment}

The "design" capacity of the west abutment, which is seated on a neoprene bearing, is calculated based on the shear capacity of one wingwall, $V_{w w}$, and the capacity of the shear 
key. As recommended by CALTRANS, the shear key capacity is taken as $0.75 \times$ R PILES,w (CALTRANS, 1988). The shear capacity of one wingwall is:

$$
\begin{aligned}
\mathrm{V}_{\mathrm{WW}} & =0.85 \times\left(V_{c}+V_{s}\right)=0.85 \times\left(0.95 \sqrt{f_{c}^{\prime}}\right) \times \text { Area }+0.85 \times \frac{A_{v} f_{y} d}{S} \\
& =0.85 \times 56.28 \times(0.75 \times 12.34 \times 144) / 1000+0.85 \times(2 \times 0.2) \times 60 \times 12.34 / 0.75 \\
& =399.40 \mathrm{kips} \quad \cdot \\
\mathrm{EQ}_{\mathrm{T}} & =\mathrm{V}_{\mathrm{WW}}+0.75 \mathrm{R}_{\mathrm{PILES}, \mathrm{W}}=399.40+0.75 \times 640 \\
& =879.40 \mathrm{kips}
\end{aligned}
$$

This capacity leads to "design" stiffness of $4397 \mathrm{kips} / \mathrm{ft}$ and $10553 \mathrm{kips} / \mathrm{ft}$ for acceptable deformation of 2.4 inch and 1 inch, respectively.

\section{AASHTO-83/ATC-6 PROCEDURE}

Following the procedure recommended by Lam and Martin (1986), initial estimate of the abutment stiffness is computed as:

$$
\begin{aligned}
\text { Stiffness } & =\text { Stiffness due to Backfill }+ \text { Stiff ness Due to Piles } \\
& =0.425 \times E_{s} \times B+\text { No. of Piles } \times 40 \text { kips } / \text { inch per pile }
\end{aligned}
$$

in which $E_{s}=1440 \mathrm{ksf}$ is the elastic modulus of the soil and B is width of the backwall or effective length of the wingwall.

The initial estimate of the longitudinal stiffness computed for the backwall width of B $=66.95 \mathrm{ft}$ and foundation consisting of 16 piles is:

$$
\begin{aligned}
\text { Stiffness } & =0.425 \times(1440 \mathrm{ksf}) \times 66.85 \mathrm{ft}+16 \times(40 \mathrm{kips} / \mathrm{inch} \times 12 \mathrm{inch} / \mathrm{ft}) \\
& =48592 \mathrm{kips} / \mathrm{ft}
\end{aligned}
$$

Similarly, initial estimate of the transverse stiffness calculated based on the effective wingwall width of $B=13.2 \mathrm{ft}$ and foundation supported on 16 piles is equal to $15758 \mathrm{kips} / \mathrm{ft}$.

\section{REFERENCES}

AASHTO-83. (1988). Guide Specifications for Seismic Design of Highway Bridges, American Association of State Highway and Transportation Officials, Washington, D.C.

ATC-6. (1981). Seismic Design Guidelines for Highway Bridges, Applied Technology Council, Berkeley, CA, October.

CALTRANS. (1989). Bridge Design Aids 14-1, California Department of Transportation, Sacramento, CA, October. 
CALTRANS. (1988). Memo to Designers 5-1, California Department of Transportation, Division of Structures, Sacramento, CA, September.

Crouse, C. B., Hushmand, B., and Martin, G. R. (1987). "Dynamic Soil-Structure Interaction of A Single-Span Bridge," Earthquake Engineering and Structural Dynamic, Vol. 15, pp. 711-729.

Douglas, B. M., Maragakis, E. A., Vrontino, S., and Douglas, B. J. (1990). "Analytical Studies of the Static and Dynamic Response of the Meloland Road Overcrossing," Proceedings of Fourth US National Conference on Earthquake Engineering, Vol. 1, pp. 987-996, Palm Springs, CA, May 20-24.

Gates, J. H. and Smith, M. J. (1982). Verification of Dynamic Modeling Method by Prototype Excitation, FHWA/CA/SD-82/07, California Department of Transportation, Office of Structures Design, Sacramento, CA, November.

Goel, R. K. and Chopra, A. K. (1990). Inelastic Seismic Response of One-Story, AsymmetricPlan Systems, Report No. UCB/EERC-90/14, Earthquake Engineering Research Center, University of California, Berkeley, CA, October.

Goel, R. K. and Chopra, A. K. (1995). Seismic Response Study of US 101/Painter Street Overpass Near Eureka Using Strong-Motion Records, CSMIP Data Utilization Report CSMIP/95-01, California Department of Conservation, Division of Mines and Geology, Office of Strong Motion Studies, March.

Lam, I. P. and Martin, G. R. (1986). Seismic Design of Highway Bridge Foundations Volume II: Design Procedures and Guidelines, Report No. FHWA/RD-86/102, Earth Technology Corporation, Long Beach, CA, June.

Levine, M. B., and Scott, R. F. (1989). "Dynamic Response Verification of Simplified BridgeFoundation Model," Journal of Geotechnical Engineering, ASCE, Vol. 115, No. 2, pp. 246-260, February.

MaCallen, D. B., and Romstad, K. M. (1994). "Dynamic Analysis of a Skewed Short-Span Box-Girder Overpass,” Earthquake Spectra, Vol. 10, No. 4, pp. 729-755, November.

Makris, N., Badoni, D., Delis, E. and Gazetas, G. (1994). "Prediction of Observed Bridge Response with Soil-Pile-Structure Interaction," Journal of Structural Engineering, Vol. 120, No. 10, pp. 2992-3011, October.

Maroney, B., Romstad, K., and Chajes, M. (1990). "Interpretation of Rio Dell Freeway Response During Six Recorded Earthquake Events," Proceedings of Fourth US National Conference on Earthquake Engineering, Vol. 1, pp. 1007-1016, Palm Springs, CA, May 20-24. 
Maroney, B., Kutter, B., Romstad, K., Chai, Y. H., and Vanderbilt, E. (1994). "Interpretation of Large Scale Bridge Abutment Test Results," Proceedings of 3rd Annual Seismic Research Workshop, California Department of Transportation, CA, June 27-29.

Romstad, K. and Maroney, B. (1990). Interpretation of Painter Street Overcrossing Records to Define Input Motions to the Bridge Superstructure, Final Report to Department of Conservation, Division of Mines and Geology, Office of Strong Motion Studies, October.

Shakal, A. F., et al. (1992). CSMIP Strong-Motion Records from the Petrolia, California Earthquakes of April 25-26, 1992, Report No. OSMS 92-05, California Department of Conservation, Division of Mines and Geology, Office of Strong Motion Studies, May 20.

Siddaharthan, R., El-Gamal, M., and Maragakis, E. A. (1995). "Influence of Free-Field Strains on Nonlinear Lateral Abutment Stiffness," Proceedings of 7th Canadian Conference on Earthquake Engineering, pp. 739-746, Montreal, Canada, June 5-7.

Sweet, J. and Morrill, K. B. (1993). "Nonlinear Soil-Structure Interaction Simulation of the Painter Street Overcrossing," Proceedings of the Second Annual CALTRANS Seismic research Workshop, Sacramento, CA, March 16-18.

Tsai, N. C. et al. (1993). Application of CALTRANS' Current Seismic Evaluation Procedures to Selected Short Bridge Overcrossing Structures, Technical Report, Dames and Moore, Oakland, CA, June.

Ventura, C. E., Finn, W. D. L., and Felber, A. J. (1995). "Ambient Vibration Study of the Painter Street Overpass," Proceedings of the 7th Canadian Conference on Earthquake Engineering, Montreal, pp. 787-794.

Werner, S. D., Crouse, C. B., Katafygiotis, L. S., and Beck, J. L. (1994). "Use of Strong Motions Records for Model Evaluation and Seismic Analysis of a Bridge Structure," Proceedings of Fifth US National Conference on Earthquake Engineering, Vol. 1, pp. 511-520, Chicago, Illinois, July 10-14.

Wilson, J. C. (1988). "Stiffness of Non-Skew Monolithic Bridge Abutments for Seismic Analysis," Earthquake Engineering and Structural Dynamics, Vol. 14, pp. 339-354.

Wilson, J. C. and Tan, B. S. (1990). "Bridge Abutments: Formulation of Simple Model for Earthquake Response Analysis," Journal of Engineering Mechanics, ASCE, Vol. 116, No. 8, pp. 1828-1856. 